Article

\title{
Bio-Fermentation Improved Rumen Fermentation and Decreased Methane Concentration of Rice Straw by Altering the Particle-Attached Microbial Community
}

\author{
Yao Xu ${ }^{1,+}$, Min Aung 1,2,+(D), Zhanying Sun ${ }^{1}$, Yaqi Zhou ${ }^{1}$, Yanfen Cheng ${ }^{1,3, * \mathbb{D}}$, Lizhuang Hao ${ }^{4}$, \\ Varijakshapanicker Padmakumar ${ }^{5}$ and Weiyun $\mathrm{Zhu}^{1}$
}

1 Laboratory of Gastrointestinal Microbiology, National Center for International Research on Animal Gut Nutrition, Nanjing Agricultural University, Nanjing 210095, China; 2019105043@stu.njau.edu.cn (Y.X.); minaung.uvs@gmail.com (M.A.); sunzhanying@njau.edu.cn (Z.S.); 2019805090@stu.njau.edu.cn (Y.Z.); zhuweiyun@njau.edu.cn (W.Z.)

2 Department of Animal Nutrition, University of Veterinary Science, Nay Pyi Taw 15013, Myanmar

3 State Key Laboratory of Grassland Agro-Ecosystems, Center for Grassland Microbiome, College of Pastoral Agriculture Science and Technology, Lanzhou University, Lanzhou 730000, China

4 Key Laboratory of Plateau Grazing Animal Nutrition and Feed Science of Qinghai Province, State Key Laboratory of Plateau Ecology and Agriculture, Qinghai Plateau Yak Research Center, Qinghai 810016, China; 2009990030@qhu.edu.cn

5 International Livestock Research Institute, Nairobi 00100, Kenya; v.padmakumar@cgiar.org

* Correspondence: yanfencheng@njau.edu.cn; Tel.: +86-25-8439-5523

+ These authors contributed equally to this work.

check for updates

Citation: Xu, Y.; Aung, M.; Sun, Z.; Zhou, Y.; Cheng, Y.; Hao, L.;

Padmakumar, V.; Zhu, W. Bio-Fermentation Improved Rumen Fermentation and Decreased Methane Concentration of Rice Straw by Altering the Particle-Attached Microbial Community. Fermentation 2022, 8, 72. https://doi.org/10.3390/ fermentation 8020072

Academic Editor: Qing Zhang

Received: 14 January 2022

Accepted: 1 February 2022

Published: 8 February 2022

Publisher's Note: MDPI stays neutral with regard to jurisdictional claims in published maps and institutional affiliations.

Copyright: (c) 2022 by the authors. Licensee MDPI, Basel, Switzerland. This article is an open access article distributed under the terms and conditions of the Creative Commons Attribution (CC BY) license (https:// creativecommons.org/licenses/by/ $4.0 /)$.

\begin{abstract}
Bio-fermentation technology has been successfully developed for ensiling rice straw; however, its effects on the particle-attached microbial community remains unknown. Therefore, rice straw (RS) and bio-fermented rice straw (BFRS) were used as substrates for in vitro rumen fermentation to investigate the effect of bio-fermentation on particle-attached microbial community, as well as their effects on gas and methane production, fermentation products, and fiber degradation. Our results have shown that total gas production, fiber degradation, and in vitro fermentation products were significantly higher $(p<0.05)$ for the BFRS than the RS, while methane concentration in total gas volume was significantly lower $(p<0.05)$ for the BFRS than RS. Linear discriminant effect size (LefSe) analysis revealed that the relative abundance of the phyla Bacteroidetes, Fibrobacteres, Proteobacteria, and Lantisphaerae, as well as the genera Fibrobacter, Saccharofermentans, and [Eubacterium] ruminantium groups in the tightly attached bacterial community, was significantly higher $(p<0.05)$ for the BFRS than the RS, whereas other microbial communities did not change. Thus, bio-fermentation altered the tightly attached bacterial community, thereby improving gas production, fiber degradation, and fermentation products. Furthermore, bio-fermentation reduced methane concentration in total gas volume without affecting the archaeal community.
\end{abstract}

Keywords: rice straw; bio-fermentation; fiber degradation; fermentation products; methane concentration; ruminal bacterial and archaea

\section{Introduction}

Ruminants are completely reliant on crops for nutrition in order to maintain proper growth, productivity, and reproduction. Rice straw is one of the most abundant crop residues in the Asian region and is used as the major roughage source for ruminant in the region. However, its recalcitrant cellulose-hemicellulose-lignin structure prevents the rumen microbes and enzymes from utilizing it, resulting in low rumen fermentation efficiency and fiber degradation [1]. Various physical and chemical approaches have been successfully developed to promote the utilization of rice straw as ruminant feed [2]; however, they have limitations. Their use leads to environmental pollution and they are high 
energy demanding. Biological approaches are currently recognized as low-energy demanding and environmentally friendly, as they do not produce any effluent or fermentation inhibitors during the process [3]. Bio-fermentation is a method that involves a combination of a number of beneficial strains into a multi-strain complex and then its inoculation into a substrate, such as RS, to promote the release of cellulose and hemicellulose for use by rumen microorganisms and improve rumen fermentability by degrading lignin, thereby increasing the nutritional value of RS [4]. Xing [5] stated that inoculation with lactic acid bacterium (LAB) could decrease fiber concentration and increase dry matter and fiber digestibility of the treated rice straw (silage). Additionally, various species of Lactobacillus inoculants improved the silage quality and feed use efficiency of low-quality roughages (such as rice straw) [6,7].

Rumen microbes degrade the dietary carbohydrates and convert them into volatile fatty acids (VFA), ammonia nitrogen $\left(\mathrm{NH}_{3}-\mathrm{N}\right)$, and microbial crude protein (MCP) for supplying nutrients to ruminants [8,9]. Rumen microbes interacting with feed particles can be functionally described as three subpopulations; those associated with rumen fluid, those loosely attached to feed particles, and those tightly attached to feed particles. Fiberdegrading enzyme activities are higher in feed particles than in the rumen fluid, thus particle-attached microbes are responsible for most of the ruminal feed digestion [10]. Without the aid of such microbes, the host ruminants cannot digest and convert plant lignocellulosic biomasses into energy and other essential metabolites [11,12]. The community composition of particle-attached microbes differs between different feeds and is likely influenced by feed chemical compositions $[13,14]$. Dietary composition is a major factor in determining the rumen microbiota community structure and metabolic activity [15]. Although the community composition of ruminal microbes attached to rice straw has been reported in our previous study [14], the effect of bio-fermentation on the community composition of ruminal microbes attached to rice straw remains unknown, despite the fact that the bio-fermentation method for ensiling rice straw has been successfully developed, as mentioned above.

Changes in the microbial community could contribute to understanding how foraging and ruminal microbes interact [16]. Research on the ruminal microbial community has become more convenient than before due to the advancement of microbial molecular techniques, particularly the high throughput sequencing technology. In vitro techniques are widely used to investigate digestibility of various forages and their effects on ruminal fermentation $[17,18]$. Therefore, the objective and the novelty of this study were to investigate the particle-attached microbial community in the bio-fermented rice straw, as well as their effects on gas and methane production, in vitro fermentation products, and fiber degradation. This information is of great significance for a deeper understanding of the colonization pattern and compositional changes of the rumen microbiome, and for the further development of bio-fermentation technology in the exploitation and utilization of roughage.

\section{Materials and Methods}

\subsection{Substrates Preparation}

The rice straw (RS) and the bio-fermented rice straw (BFRS) used in this experiment were purchased from Zhongxin Agricultural Service Professional Cooperative, Yancheng City, Jiangsu Province, China. For bio-fermenting rice straw, after harvesting rice in the field, the rice straw was picked up and shipped to the factory. The "S102 straw micro-storage" silage inoculant was supplied by the Jiangsu Academy of Agricultural Sciences. The rate of application of inoculant per kilogram of rice straw was $2 \times 10^{8} \mathrm{CFU} / \mathrm{kg}$. Thereafter, it was wrapped in a polyethylene sheet and fermented for 40 days. The chemical compositions of the RS and the BFRS are presented in Table S1. 


\subsection{In Vitro Rumen Fermentation and Sample Collection}

Four ruminally cannulated $\mathrm{Hu}$ sheep were used as the donor of rumen fluid. The sheep were fed a total mixed ration ( $40 \%$ alfalfa hay and $60 \%$ concentrate) twice a day (8:00 a.m. and 4:00 p.m.). All animal procedures were carried out using the protocols approved by the Animal Care and Use Committee of Nanjing Agricultural University, 1999. Rumen fluid was collected before morning feeding, filtered through 4 layers of sterile cheesecloth, and mixed in equal amounts from each animal. The buffered rumen inoculum was prepared by mixing the composite rumen fluid with artificial saliva $(1: 9, v / v)$ [19]. One gram of substrate, i.e., the RS or the BFRS, was introduced in 4 replicates into the $180 \mathrm{~mL}$ serum bottle, followed by the addition of $100 \mathrm{~mL}$ of buffered rumen inoculum under $\mathrm{CO}_{2}$ steam. A blank incubation without substrate was also taken for correction of gases. All bottles were incubated at $39{ }^{\circ} \mathrm{C}$ for $24 \mathrm{~h}$ without shaking, and cumulative gas production was measured with a pressure transducer at $2,4,6,8,10,12,16,20$, and $24 \mathrm{~h}$ [20]. At each time point, about $5 \mathrm{~mL}$ gas from each bottle was collected into a gas-tight aluminum bag (Dalian Delin Gaspacking limited company, Dalian, China) for methane analysis. At $24 \mathrm{~h}$ of fermentation, four bottles from each group were taken out and placed in ice to cease the fermentation. From each bottle, an aliquot of about $2 \mathrm{~mL}$ supernatant was transferred into four $3 \mathrm{~mL}$ capacity tubes and stored at $-20^{\circ} \mathrm{C}$ for the analysis of fermentation products. Isolation of the loosely attached fraction (L) and tightly attached fraction (T) was followed by the procedure described by Larue et al. [21]. One gram of residues from each bottle was sampled into $5 \mathrm{~mL}$ capacity tubes before adding $5 \mathrm{~mL}$ phosphate buffer saline (PBS) and shaking for $30 \mathrm{~s}$. Then, the supernatant obtained by centrifugation $(15 \mathrm{~min}, 350 \times \mathrm{g})$ was defined as a loosely attached fraction, while the solid residue was defined as a tightly attached fraction. These fractions were stored at $-80^{\circ} \mathrm{C}$ until analysis of the bacterial and archaeal community was loosely or tightly attached to the substrates. After taking the samples, the $\mathrm{pH}$ was immediately measured. The remaining residues were washed and dried at $105{ }^{\circ} \mathrm{C}$ until the weight remained constant, to determine the in vitro nutrient digestibility.

\subsection{Analysis of In Vitro Fiber Digestibility of Substrates}

The substrates were transferred into the $50 \mathrm{~mL}$ pre-weighed centrifuge tubes and dried at $105^{\circ} \mathrm{C}$. The dry matter (DM) content was analyzed according to AOAC [22], and the contents of neutral detergent fiber (NDF), acid detergent fiber (ADF), acid detergent lignin (ADL), hemicellulose $(\mathrm{H})$, and cellulose $(\mathrm{C})$ were analyzed by the ANKOM filter bag technique using an ANKOM 200i fiber analyzer (ANKOM Technologies, Inc., Fairport, NY, USA) [23]. Dry matter and nutrient digestibilities were calculated using the model: digestibility $(\%)=[(\mathrm{A}-\mathrm{B}) / \mathrm{A}] \times 100$, where " $\mathrm{A}$ " meant the amount of nutrient before fermentation and " $\mathrm{B}$ " referred to the amount of nutrient after fermentation.

\subsection{Analysis of Substrate Fermentation Products}

The $\mathrm{pH}$ was measured with a $\mathrm{pH}$ meter (Ecoscan $\mathrm{pH} 5$, Singapore). Lactate was determined with the Lactate Assay Kit (Nanjing Jiancheng Bioengineering Institute, Nanjing, China) and $\mathrm{NH}_{3}-\mathrm{N}$ was measured with the method of Weatherburn [24]. Microbial crude protein (MCP) was determined with Bradford Protein Assay Kit (Beijing Solarbio Science and Technology Company, Beijing, China), while the volatile fatty acids (VFAs) were analyzed with the GC (Daojin GC2014AFsc instrument, Shimadzu, Japan). The conditions used for the GC analysis were as follows: a column temperature of $135^{\circ} \mathrm{C}$, an injection temperature of $200{ }^{\circ} \mathrm{C}$, FID detector temperature of $200{ }^{\circ} \mathrm{C}$, and a carrier gas $\left(\mathrm{N}_{2}\right)$ pressure of $0.06 \mathrm{MPa}$ [25]. Methane was analyzed by the GC-TCD (Agilent 7890B, Agilent, Santa Clara, CA, USA). The condition used for GC-TCD analysis were: a column temperature of $80^{\circ} \mathrm{C}$, an injection temperature of $200^{\circ} \mathrm{C}$, a TCD detector temperature of $200{ }^{\circ} \mathrm{C}$, and a carrier gas $\left(\mathrm{N}_{2}\right)$ pressure of $0.05 \mathrm{MPa}$ [26]. 
2.5. Analysis of Bacteria and Archaea Loosely or Tightly Attached to Substrates by Illumina Hiseq Sequencing of $16 S$ Rrna Gene

The samples from $\mathrm{L}(1 \mathrm{~mL})$ and $\mathrm{T}(0.3 \mathrm{~g})$ fractions were used for DNA extraction using the bead-beating and phenol-chloroform extraction method proposed by Zoetendal et al. [27]. After DNA extraction, a PCR thermal cycler (Eppendorf AG 22331 Hamburg, German) was used to amplify the total bacterial and archaeal $16 \mathrm{~S}$ rRNA gene. The universal primers, $515 \mathrm{~F}$ 5'-GTGCCAGCMGCCGCGGTAA-3' and 806R 5'-GGACTACHVGGGTWTCTAAT-3' [28], and Ar915F 5'-AGGAATTGGCGGGGGAGCAC-3' and Ar1386R 5'-GCGGTGTGTGCAAGGAGC$3^{\prime}$ [29], targeting the 16S rRNA gene were used to obtain the PCR amplicons of total bacteria and archaea, respectively. The PCR amplicons were then purified by means of Agencourt AMPure XP beads (Beckman Coulter, Milan, Italy). The RNA concentration was quantified with a Small RNA Kit (Agilent Technologies, 5067-1548, Beijing, China) and 2100 Bioanalyzer. Amplified libraries were sequenced on an Illumina Hiseq platform at BGI Life Tech Co., Ltd. (Beijing, China).

To remove ambiguous and low-quality sequences, the raw sequencing data were preprocessed with cutadapt v2.6 software [30]. After trimming, the sequence data were further quality-filtered to abandon reads with ambiguous, homologous sequences. If the window average quality value was $<20$, the end of the read sequence was truncated from the window, and the reads with a final read length $<75 \%$ of the original read length were removed. Then, the reads with chimera were detected and removed by QIIME 2 software [31]. After the pretreatment described above, clean reads were grouped into amplicon sequence variant (ASV) using Vsearch software at a 99\% similarity level. The representative read of each ASV was selected by using the QIIME package in bacterial and archaeal community was annotated by the SILVA 16 S rRNA database and the RIM database, respectively. Alpha diversity, as indicated by the number of ASV, Evenness, Faith's phylogenetic diversity (Faith_pd), and Shannon, was calculated with QIIME 2 software. Evenness described the relative abundance of the different species making up the richness. Faith_pd was used to calculate the alpha diversity. The Shannon index was used for microbial diversity analysis. A Venn diagram was used to visualize the number of common and unique features. The unweighted UniFrac distance was used for principal coordinate analysis (PCoA) to compare the microbial communities between two groups. Linear discriminant analysis effect size (LEfSe) analysis was also employed to determine the significant differences in the bacterial community between the two groups.

\subsection{Statistical Analysis}

The data of total gas production, methane concentration, fiber degradation, fermentation products, and alpha diversity of bacteria or archaea were statistically analyzed by SPSS 25.0 (SPSS, Chicago, IL, USA) with the independent $t$-test. Statistical significance was defined at $p<0.05$. Venn diagrams and PCoA analysis were completed by the online data visualization and analysis tool (https: / / www.bioincloud.tech/task-meta/ (accessed on 10 January 2022)). LEfSe analysis was performed by the online LEfSe analysis tool (http:/ / huttenhower.sph.harvard.edu/galaxy/ (accessed on 10 January 2022)) [32]. All the data were shown as mean \pm standard error of mean (SEM) and plotted in GraphPad Prism 8.0.

\section{Results}

3.1. Effect of Bio-Fermentation on Gas Production, Methane Concentration, Fiber Degradation and In Vitro Fermentation Products of Rice Straw

The total gas production curves (Figure 1A) showed that the values were significantly higher $(p<0.05)$ for the BFRS than the RS at the all-time points. Conversely, the methane concentration (in total gas) curves (Figure 1B) demonstrated that the values were significantly lower $(p<0.05)$ for the BFRS than the RS. 
(A)

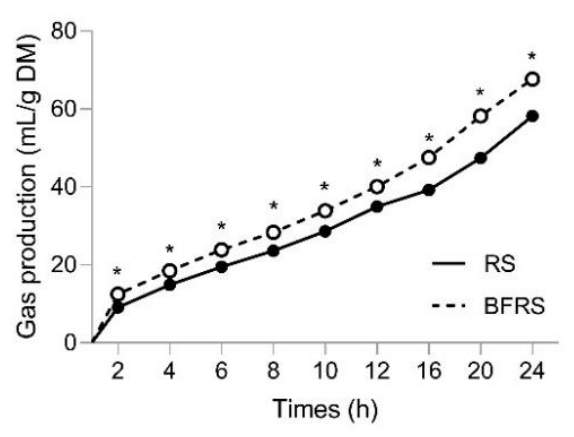

(B)

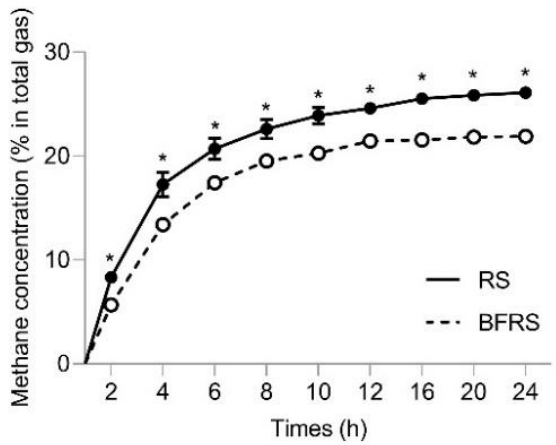

Figure 1. Curves of cumulative total gas production (A) and methane concentration (B) for the RS and the BFRS. Asterisks $\left(^{*}\right)$ indicate the significant difference $(p<0.05)$ between groups at the same time of incubation. RS: rice straw, BFRS: bio-fermented rice straw.

The digestibility of dry matter, NDF, ADF, hemicellulose, and cellulose of the BFRS were significantly higher $(p<0.05)$ than those of RS, while digestibility of ADL was not different $(p>0.05)$ between the RS and the BFRS (Table 1). The $\mathrm{pH}$ did not differ $(p>0.05)$ between the two groups. The fermentation products, total VFA, acetate, propionate and valerate concentrations for the BFRS were greater $(p<0.05)$ than those for the RS. However, acetate to propionate ratio, isobutyrate, butyrate, and isovalerate concentrations were not different $(p>0.05)$ between the groups. Likewise, the concentrations of lactate, $\mathrm{NH}_{3}-\mathrm{N}$, and MCP were higher $(p<0.05)$ for the BFRS than the RS (Table 1$)$.

Table 1. Effect of the bio-fermentation on fiber digestibility and fermentation products in the rice straw fermentation at $24 \mathrm{~h}$ incubation.

\begin{tabular}{ccc}
\hline Items & \multicolumn{2}{c}{ Groups } \\
\cline { 2 - 3 } & RS & BFRS \\
\hline Fiber digestibility & & \\
DMD, $\%$ & $26.44 \pm 0.64 \mathrm{~b}$ & $31.27 \pm 1.11 \mathrm{a}$ \\
NDFD, $\%$ & $32.93 \pm 0.86 \mathrm{~b}$ & $38.50 \pm 1.31 \mathrm{a}$ \\
ADFD, $\%$ & $23.94 \pm 0.98 \mathrm{~b}$ & $31.76 \pm 2.10 \mathrm{a}$ \\
ADLD, \% & $50.26 \pm 1.95$ & $47.06 \pm 2.28$ \\
HD, \% & $41.65 \pm 0.83 \mathrm{~b}$ & $45.81 \pm 1.00 \mathrm{a}$ \\
CD, $\%$ & $23.66 \pm 1.40 \mathrm{~b}$ & $32.81 \pm 1.03 \mathrm{a}$ \\
pH & & \\
Fermentation products & $6.76 \pm 0.03$ & $6.75 \pm 0.02$ \\
Total VFA (mmol/L) & $51.78 \pm 0.70 \mathrm{~b}$ & $56.16 \pm 0.27 \mathrm{a}$ \\
Acetate (mmol/L) & $30.65 \pm 0.50 \mathrm{~b}$ & $33.52 \pm 0.43 \mathrm{a}$ \\
Propionate (mmol/L) & $11.65 \pm 0.18 \mathrm{~b}$ & $13.03 \pm 0.19 \mathrm{a}$ \\
Acetate: Propionate & $2.63 \pm 0.04$ & $2.57 \pm 0.04$ \\
Isobutyrate (mmol/L) & $0.99 \pm 0.01$ & $0.97 \pm 0.02$ \\
Butyrate (mmol/L) & $6.52 \pm 0.16$ & $6.57 \pm 0.19$ \\
Isovalerate (mmol/L) & $1.50 \pm 0.04$ & $1.47 \pm 0.08$ \\
Valerate (mmol/L) & $0.48 \pm 0.01 \mathrm{~b}$ & $0.60 \pm 0.01 \mathrm{a}$ \\
Lactate (mmol/L) & $0.16 \pm 0.01 \mathrm{~b}$ & $0.21 \pm 0.01 \mathrm{a}$ \\
NH ${ }_{3}-\mathrm{N}$ (mg/dL) & $9.81 \pm 0.16 \mathrm{~b}$ & $11.02 \pm 0.26 \mathrm{a}$ \\
MCP (mg/dL) & $10.36 \pm 0.37 \mathrm{~b}$ & $12.05 \pm 0.31 \mathrm{a}$ \\
\hline
\end{tabular}

DMD: dry matter digestibility, NDFD: neutral detergent fiber digestibility, ADFD: acid detergent fiber digestibility, ADLD: acid detergent lignin digestibility, HD: hemicellulose digestibility, CD: cellulose digestibility, VFA: volatile fatty acid, $\mathrm{NH}_{3}-\mathrm{N}$ : ammonia nitrogen, $\mathrm{MCP}$ : microbial crude protein, RS: rice straw, BFRS: bio-fermented rice straw. Different letters $(\mathrm{a}, \mathrm{b})$ indicate a significant difference at $p<0.05$. 
3.2. Effect of Bio-Fermentation on Loosely Attached Bacterial and Archaeal Community during In Vitro Rumen Fermentation

For the bacterial and archaeal community analyses of the loosely attached fraction, a total of 593,508 and 375,594 sequences remained from eight samples after quality filtering with a mean of $74,189 \pm 21$ and 44,699 \pm 1577 sequences per sample, respectively. A total of 614 and 165 amplicon sequence variants (ASV) were identified at the $99 \%$ similarity level for the bacterial and archaeal communities in the loosely bound fraction, respectively. The bio-fermentation had no effect $(p>0.05)$ on the alpha diversity of bacteria and archaea loosely attached to RS (Table 2).

Table 2. Effect of the bio-fermentation on alpha diversity of loosely and tightly attached bacteria and archaea in the rice straw fermentation.

\begin{tabular}{ccccc}
\hline \multirow{2}{*}{ Items } & \multicolumn{2}{c}{ Loosely Attached Fraction } & \multicolumn{2}{c}{ Tightly Attached Fraction } \\
\cline { 2 - 5 } & RS & BFRS & RS & BFRS \\
\hline Bacteria & & & & \\
Number of ASV & $355.75 \pm 2.06$ & $350.50 \pm 20.34$ & $448.75 \pm 8.59$ & $461.50 \pm 3.59$ \\
Evenness & $0.74 \pm 0.00$ & $0.72 \pm 0.03$ & $0.75 \pm 0.00 \mathrm{~b}$ & $0.76 \pm 0.00 \mathrm{a}$ \\
Faith_pd & $27.10 \pm 0.22$ & $25.78 \pm 0.85$ & $29.99 \pm 0.35$ & $30.56 \pm 0.18$ \\
Shannon & $6.25 \pm 0.03$ & $6.08 \pm 0.31$ & $6.55 \pm 0.04 \mathrm{~b}$ & $6.72 \pm 0.04 \mathrm{a}$ \\
Archaea & & & & \\
Number of ASV & $55.00 \pm 12.08$ & $49.00 \pm 8.69$ & $96.50 \pm 16.66$ & $96.25 \pm 16.75$ \\
Evenness & $0.60 \pm 0.02$ & $0.51 \pm 0.07$ & $0.58 \pm 0.01$ & $0.58 \pm 0.01$ \\
Faith_pd & $24.96 \pm 6.69$ & $22.98 \pm 5.25$ & $42.93 \pm 10.16$ & $45.55 \pm 8.85$ \\
Shannon & $3.43 \pm 0.26$ & $2.78 \pm 0.36$ & $3.81 \pm 0.18$ & $3.79 \pm 0.11$ \\
\hline
\end{tabular}

ASV: amplicon sequence variant, RS: rice straw, BFRS: bio-fermented rice straw. Different letters $(a, b)$ indicate a significant difference at $p<0.05$.

Venn diagrams for the loosely attached fraction demonstrated that there were 427 common taxa and 57 and 130 unique taxa for the bacterial community (Figure 2A), as well as 68 common taxa and 47 and 50 unique taxa for the archaeal community (Figure 2C) of RS and BFRS, respectively. The PCoA showed that the loosely attached bacteria (Figure 2B) or archaea (Figure 2D) in the RS and the BFRS fermentations did not cluster separately.

Loosely fraction

(A)

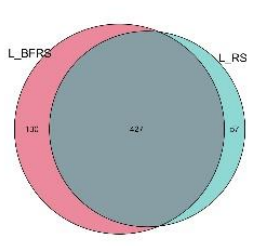

Tightly fraction

(E)

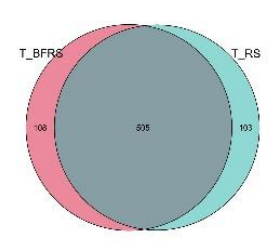

(B)

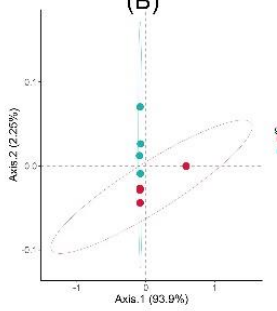

(F)

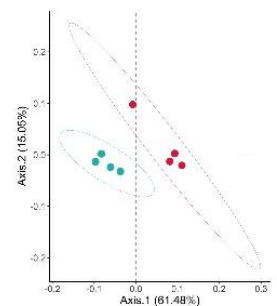

(C)

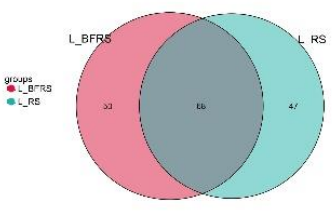

(G)

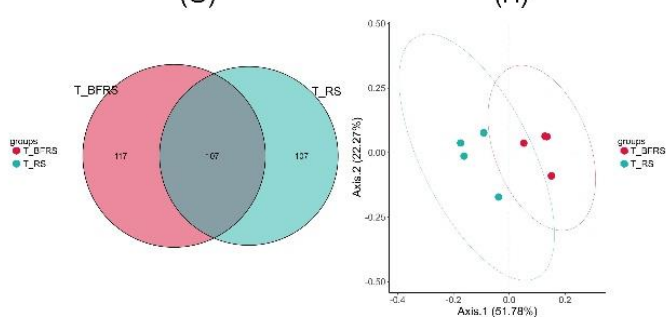

Figure 2. Venn diagrams of loosely attached bacteria (A) and archaea (C), and tightly attached bacteria (E) and archaea (G), and PCoA plots of loosely attached bacteria (B) and archaea (D), and tightly attached bacteria (F) and archaea (H), for the RS and the BFRS. RS: rice straw, BFRS: bio-fermented rice straw. 
Six bacteria phyla were identified with relative abundances of more than $0.5 \%$ in at least one group, whereas Bacteroidetes, Firmicutes, and Proteobacteria were most abundant, accounting for $96 \%$ of total loosely attached bacteria (Figure $3 \mathrm{~A}$ ). The relative abundances of 14 bacteria genera were also above $1.0 \%$ in at least one group, whereas Prevotella 1 , the Rikenellaceae RC9 gut group, and Succinivibrio were most abundant, representing about $62 \%$ of total loosely attached bacteria (Figure 3B). Three archaeal families were detected in this study, whereas Methanobacteriaceae was the most dominant family of archaea, accounting for $83 \%$ of the total loosely attached archaea (Figure 3C). Six genera of archaea were identified with relative abundance of more than $1.0 \%$ in at least one group, whereas Methanobrevibacter, Methanotorris, and Methanomassiliicoccaceae_Group9 were most abundant, representing about $97 \%$ of the total loosely attached archaea (Figure 3D).

(A)

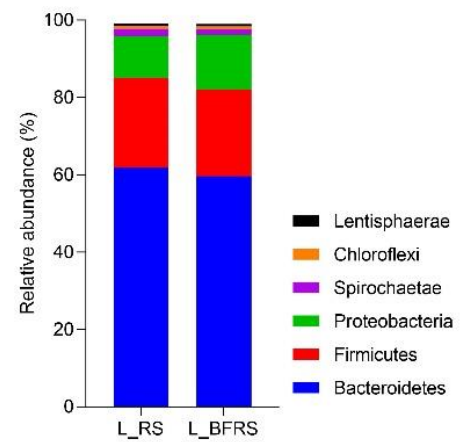

(C)

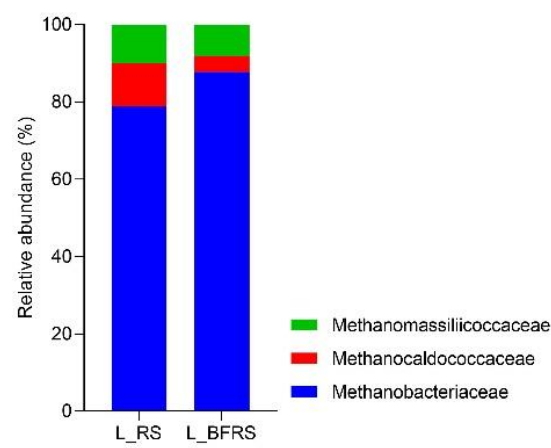

(B)

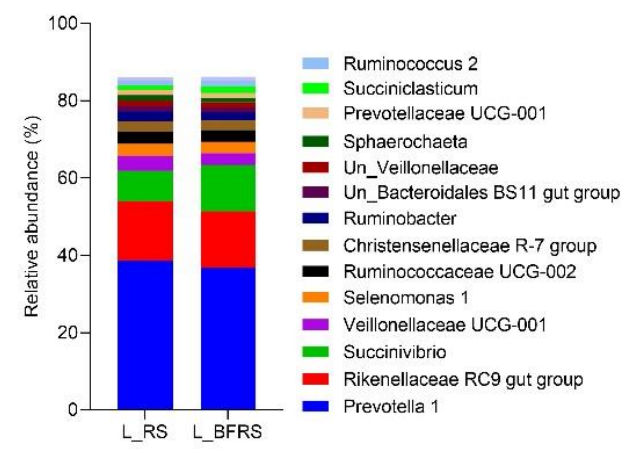

(D)

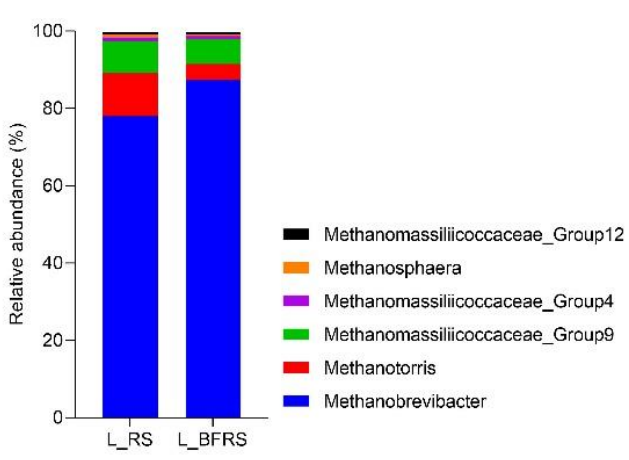

Figure 3. Relative abundance of loosely attached bacteria at phylum level (A) and genus level (B), and archaea at family level (C) and genus level (D) for the RS and the BFRS (the average relative abundances of phyla or family $>0.5 \%$, and genera $>1.0 \%$ in at least one group are presented). RS: rice straw, BFRS: bio-fermented rice straw.

The LEfSe analysis (from phyla to genus level) was performed for loosely attached bacterial and archaeal communities. Only uncultured Lachnospiraceae belonging to the phyla Firmicutes for the bacterial community (Figure S1A) and Methanosphaera belonging to the family Methanocaldococcaceae for the archaeal community (Figure S1B) were higher in RS.

\subsection{Effect of Bio-Fermentation on the Tightly Attached Bacterial and Archaeal Community during} the In Vitro Rumen Fermentation

For the bacterial and archaeal community analyses of the tightly attached fraction, a total of 593,631 and 347,606 sequences remained from eight samples after quality filtering with a mean of $74,204 \pm 16$ and 43,451 \pm 631 sequences per sample, respectively. Totals of 716 and 331 amplicon sequence variants (ASV) were identified at the 99\% similarity level for the bacterial and archaeal communities of the tightly attached fraction, respectively. 
Alpha diversity of bacteria tightly attached to the RS was significantly changed by the bio-fermentation, whereas Evenness and Shannon were significantly higher $(p<0.05)$ for the BFRS than the RS. However, alpha diversity of archaea tightly attached to RS did not differ $(p>0.05)$.

Venn diagrams for tightly fraction revealed that there were 505 common taxa and 103 and 108 unique taxa for bacteria community (Figure 2E), and 107 common taxa and 107 and 117 unique taxa for archaea community (Figure 2G) in the RS and BFRS fermentations, respectively. The PCoA displayed that tightly attached bacterial communities of the RS and the BFRS fermentations were clustered into two separate groups (Figure 2F), while archaea were not clustered separately (Figure $2 \mathrm{H}$ ).

Eight bacteria phyla were identified with relative abundances of more than $0.5 \%$ in at least one group, whereas Bacteroidetes and Firmicutes were most abundant, accounting for $89 \%$ of total tightly attached bacteria (Figure $4 \mathrm{~A}$ ). The relative abundances of 17 bacteria genera were also above $1.0 \%$ in at least one group, whereas Prevotella 1 was the most abundant accounting for $29 \%$, followed by the Rikenellaceae RC9 gut group (14\%), Probable genus $10(8 \%)$, the uncultured Bacteroidales S24-7 group (8\%), and the Christensenellaceae R-7 group (5\%) of the total tightly attached bacteria (Figure $4 \mathrm{~B}$ ). Three archaeal families were detected in this study, whereas Methanobacteriaceae was the most dominant family of archaea, accounting for $70 \%$ of the total tightly attached archaea (Figure $4 \mathrm{C}$ ). Seven genera of archaea were identified with relative abundance of more than $1.0 \%$ in at least one group, whereas Methanobrevibacter and Methanotorris were the most abundant, representing about $88 \%$ of the total tightly attached archaea (Figure $4 \mathrm{D})$.

(A)

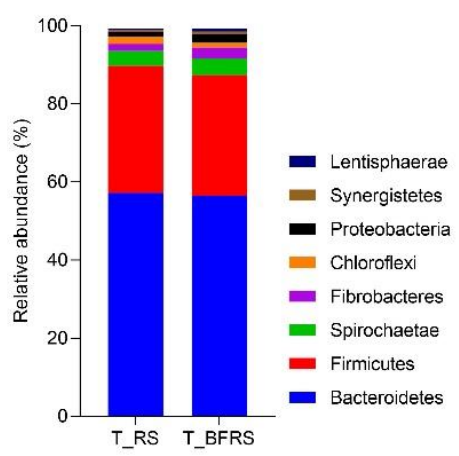

(C)

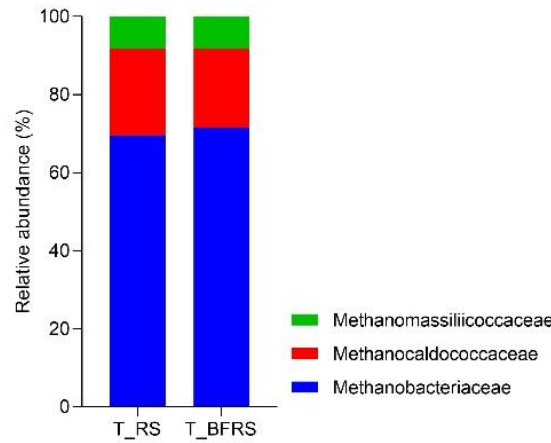

(B)

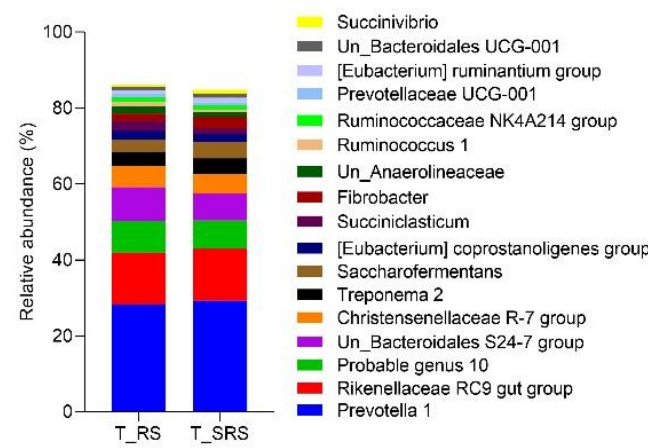

(D)

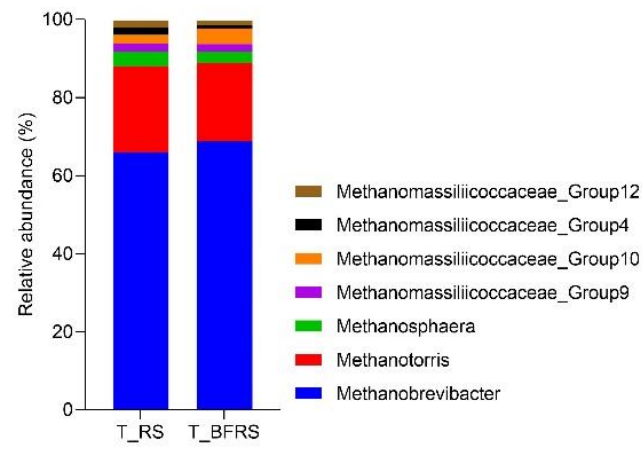

Figure 4. Relative abundance of tightly attached bacteria at phylum level (A) and genus level (B), and archaea at family level (C) and genus level (D) for the RS and the BFRS (the average relative abundances of phyla or family $>0.5 \%$, and genera $>1.0 \%$ in at least one group are presented). RS: rice straw, BFRS: bio-fermented rice straw.

The LEfSe analysis (from phyla to genus level) was performed for tightly attached bacterial and archaeal community. For the bacterial community, eight bacterial phyla 
were significantly different, whereas two phyla were higher for the RS and six phyla were higher for the BFRS. Among those bacterial phyla with the relative abundance of $>0.5 \%$ in at least one sample, Chloroflexi was higher for the RS, and Bacteroidetes, Fibrobacteres, Proteobacteria, and Lentisphaerae were higher for the BFRS (Figure 5A). At the genus level, 44 genera were significantly different, whereas 21 genera were higher for the RS and 23 genera were higher for the BFRS (Figure 5A). Among those bacterial genera with the relative abundance $>1.0 \%$ in at least one sample, Ruminococcus 1 and Prevotellaceae UCG-001 were higher for the RS, and Fibrobacter, Saccharofermentans, and [Eubacterium] ruminantium groups were higher for the BFRS (Figure 5B). For the archaeal community, the genera group 4 and group 10, belonging to the Methanomassiliicoccaceae family, were higher for the RS and the BFRS, respectively (Figure S1C).

(A)

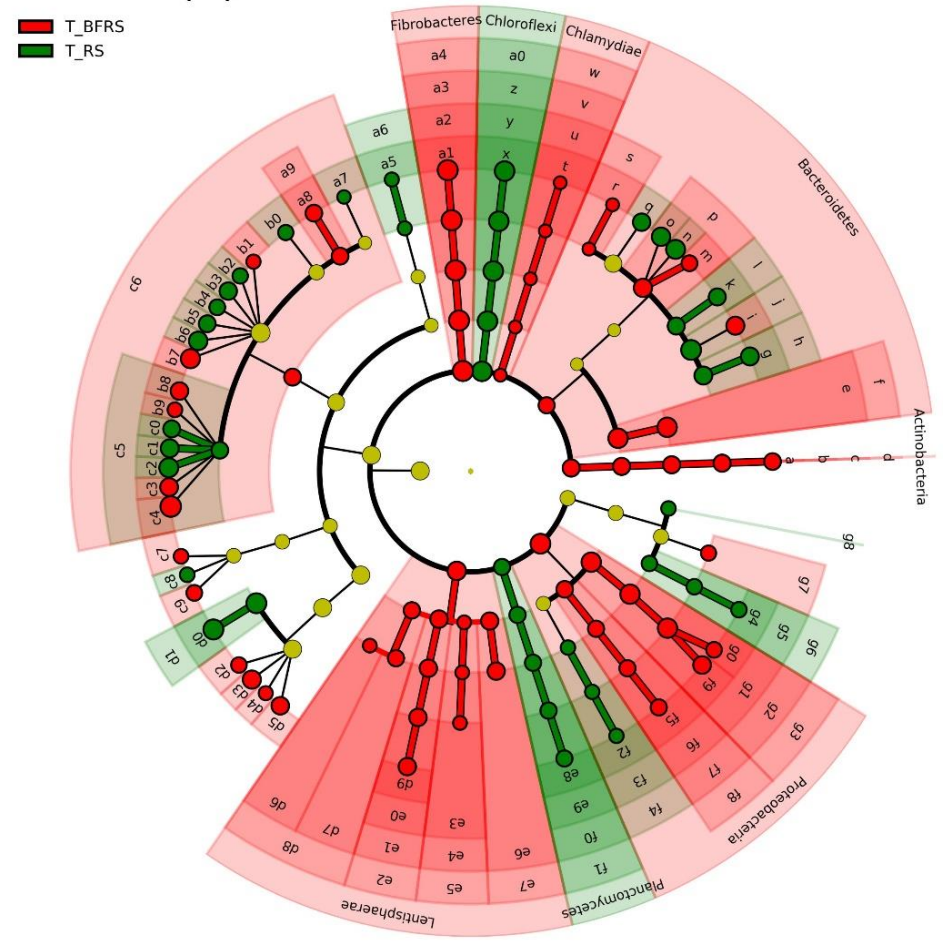

믈 : Atopobium

b: Coriobacteriacea

d: Coriobacteriia

f: : BacteroidetesVC2_1Bac22

g: Bacteroides

i: unculturedbacterium

j: BacteroidalesBS1 1 gutgroup

k: Phocaeicola

I: BacteroidalesIncertaeSedis

m: Prevotella

n: PrevotellaceaeUCG_001

o: PrevotellaceaeUCG_o

9. U29.803

s: uncultured

t: unculturedrur

u: WA_aaa01f12

v: Chlamydiales

w: Chlamydiae

x: Ancultured

z: Anaerolineales

a.: Anaerolineae

므 a2: Fibrobacteracea

a3: Fibrobacterales

a4: Fibrobacteria

a5: Thermoactinomyces

a6: Thermoactinomycetaceae

a8: Pseudoramibacter

ag: Eubacteriaceae

Do: FamilyXIIIUCG_002

b1: Lachnoclostridium

b2: Lachnoclostridium1

b3: Lachnoclostridium10

3007 grou

b5: Moryella

b7:_Eubacterium_ruminantiumgrou

b8: RuminococcaceeeUCG_002

b9: RuminococcaceaeUCG_ 00

c0: RuminococcaceaeUCG 011

c1: RuminococcaceaeucG_01 01

c2: Ruminococcus1

(B)

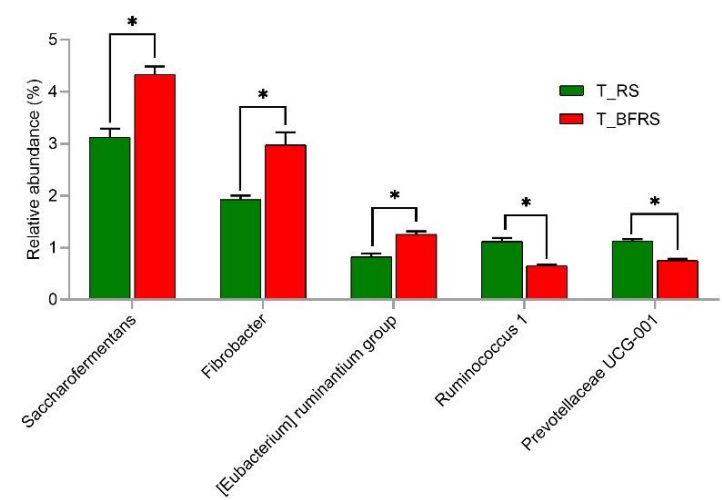

Figure 5. LEfSe analysis of the tightly attached bacterial community in the RS and the BFRS fermentations. Cladogram showing significantly enriched bacterial taxa from phylum to genus level (A), and comparison of significantly different bacterial genera (B). Asterisks ${ }^{*}$ ) indicate the significant difference $(p<0.05)$ between groups. RS: rice straw, BFRS: bio-fermented rice straw. 


\section{Discussion}

The in vitro rumen fermentation technique does not necessitate expensive equipment, and the large numbers of samples can be incubated and analyzed at the same time. This technique simulates the rumen fermentation process and has been used to evaluate the potential of feed for supplying nutrients to ruminants. Likewise, this technique can be used to investigate feed methane production, which is a waste of feed energy and a source of global warming. Thus, in this study, the in vitro rumen fermentation technique was used to evaluate the total gas and methane production, fiber degradation, and microbial community attached to bio-fermented rice straw.

The chemical composition of substrates, particularly the fiber content of feed, was found to be negatively associated with the gas production [33,34]. The low content of fiber can facilitate the utilization of feed by ruminal microbes, resulting in higher fermentation rates [35]. This assertion supported our results on gas production, which was higher for BFRS, with lower NDF and hemicellulose, and higher NDS contents. Furthermore, the gas production is a reflection of carbohydrate fractions and degradation $[36,37]$. Subsequently, the lignocellulose degradation of substrates in rumen in vitro fermentation was investigated. As the results show, a higher degradation of DM, NDF, ADF, hemicellulose, and cellulose was observed for the BFRS compared to the RS. This is likely due to the higher NDS and lower fiber (NDF, ADL, and hemicellulose) contents of the BFRS, which could lead to increased DM degradation, gas production, and fermentation rate. Zhang et al. [38] reported that RS with higher NDS content had higher in vitro DM degradation and gas production. Moreover, Gharechahi et al. [39] stated that the total DM degradation was mainly determined by NDF content of forages, which is consistent with lower NDF content and higher DM degradation of BRFS observed in our study.

The fermentation products are negatively related to the fiber contents [40], and positively correlated with non-fibrous carbohydrate (NFC) content [41] of substrates. Lactate, an intermediary product, is mainly produced from the fermentation of easily fermentable feed, and then metabolized to VFAs, the end products of rumen microbial fermentation [23]. This is congruent with our findings, which showed that the BFRS with lower NDF and higher NDS contents had higher lactate and VFA, especially total VFA, acetate, and propionate concentrations, than those for the RS. Protease hydrolyzes proteins into amino acids and peptides, while microbial deamination converts some of the amino acids to ammonia [42]. A portion of ammonia is converted to MCP by bacteria, while the rest is absorbed into the blood and contributes to the rumen nitrogen cycle [43]. In our study, protein contents of two substrates were similar; however, $\mathrm{NH}_{3}-\mathrm{N}$ and $\mathrm{MCP}$ were higher in the BFRS than the RS fermentations. This could be attributed to the enhanced protein breakdown into ammonia by the bio-fermentation and higher MCP synthesis from ammonia.

The rumen microbes degrade the dietary nutrients and convert them into VFA, $\mathrm{NH}_{3}-\mathrm{N}$, and MCP for supplying nutrients to ruminants. Carbohydrates, especially fibrous carbohydrates, are mainly degraded by the microbes attached to feed particles [8,9]. Among the alpha diversity of bacteria and archaea in both the loosely and tightly attached fractions, the bacterial alpha diversity (Evenness and Shannon) in the tightly attached fraction was significantly higher for the BFRS than the RS, which was supported by the PCoA plots, where the tightly attached bacterial communities of the RS and the BFRS were clustered into two separate groups.

The bacterial compositional analysis showed that Bacteroidetes and Firmicutes were the most abundant bacterial phyla in both the loosely and tightly attached fractions. This finding is consistent with the report of Cheng et al. [14], who found Bacteroidetes and Firmicutes to be the most dominant bacterial phyla present both in loosely and tightly attached fractions to rice straw. Bacteria belonging to these two phyla, Bacteroidetes and Firmicutes, were associated with the fiber degradation and polysaccharide degradation $[44,45]$, and are considered to be the primary degrader of complex soluble polysaccharides in plant cell walls [46,47]. At the genus level, the Prevotella 1 and Rikenellaceae RC9 gut groups 
were also the most abundant bacterial genera in both loosely and tightly attached fractions. Xie et al. [48] reported that the Prevotella 1 and Rikenellaceae RC9 gut groups were most abundant bacterial genera in the rumen of $\mathrm{Hu}$ sheep. Prevotella has a great functional versatility and is mainly involved in carbohydrate and nitrogen metabolisms in the rumen, as well as in producing a variety of enzymes involved in the degradation of starch, proteins, peptides, and hemicellulose [49,50]. Propionate synthesis by Prevotella spp. is important for maintaining glucose homeostasis in host animals through gluconeogenesis [49]. The Rikenellaceae RC9 gut group is associated with primary or secondary carbohydrate degradation and protein fermentation $[51,52]$.

The LEfSe analysis of loosely attached bacterial community demonstrated that only taxa, uncultured Lachnospiraceae belonging to the phyla Firmicutes, was higher in the RS. In the tightly attached bacterial community, the bio-fermentation improved the relative abundance of the phyla Bacteroidetes, Fibrobacteres, Proteobacteria, and Lantisphaerae, as well as the genera Fibrobacter, Saccharofermentans, and [Eubacterium] ruminantium groups for rice straw. This is likely due to the destruction of lignocellulosic structure of rice straw by the bio-fermentation treatment, which facilitated the colonization and growth of microorganisms [53]. Bacteroidetes have high saccharolytic activities and are involved in pectin, hemicellulose, and cellulose degradation [54,55], which may be attribute to the exposure of lignocellulosic structures in BFRS. Proteobacteria is mainly involved in the nitrogen metabolism in the rumen [56], and higher concentration of $\mathrm{NH}_{3}-\mathrm{N}$ in BFRS may be responsible for the increase in Proteobacteria. Fibrobacteres and its genus, Fibrobacter, are recognized as the cellulolytic bacteria, which produces cellulolytic enzymes capable of degrading cellulose [57,58], and converts feeds into VFA [59]. This also explains why the BFRS group possesses higher DMD, CD, HD, and VFAs. Saccharofermentans are the sugar-fermenting bacteria and utilize glucose as a substrate for fermentation to produce acetate [60]. Moreover, they are associated with the digestibilities of ADF and cellulose [61], which is consistent with the higher digestibilities of ADF and cellulose for the BFRS observed in our study. [Eubacterium] ruminantium, the hemicellulose fermenter, is recognized as the fibrolytic bacteria [62]. Its higher relative abundance in BFRS indicates its involvement in hemicellulose degradation. As mentioned above, bio-fermentation increased the relative abundances of bacteria related to cellulose and hemicellulose degradation, as well as nitrogen metabolism, thereby improving the fiber degradation and fermentation profile.

Feed fermentation, degradation, and digestion depend on the attachment of rumen bacteria to feed particles. The makeup of the rumen microbial community, which influences fermentation products and ruminal $\mathrm{pH}$, could be altered by the physicochemical qualities of feed $[15,63]$. Changes in the microbial community could help in understanding how forage and ruminal microorganisms interact [16]. However, the effect of bio-fermentation on changes in physicochemical properties of rice straw was not studied in this work, which needs investigation for a better understanding of the bio-fermentation process that increased the nutritional value of rice straw.

Methane emission from enteric fermentation is the waste of energy ingested by ruminant, and is also a significant source of greenhouse gas, accounting for approximately $10-12 \%$ of global methane emissions [64]. In our study, the methane concentration in total gas volume was lower for the BFRS than the RS, without changes in the archaeal composition. This is likely due to the higher concentration of organic acids in the BFRS fermentation, which could inhibit the ability of archaea to use $\mathrm{H}_{2}$ for methane production, without affecting the archaeal population [65].

As for the archaeal composition, only the three families were detected in both loosely and tightly attached fractions, where Methanobacteriaceae was the most abundant, followed by Methanocaldococcaceae and Methanomassiliicoccaceae. At the genus level, Methanobrevibacter and Methanotorris were the most abundant archaeal genera in both loosely and tightly attached fractions. Huang and Li [66] stated that Methanobrevibacter is the most dominant archaeal genus in the rumen of Tibetan sheep and Gansu Alpine Finewool sheep. Xie et al. [48] also reported that the Methanobacteriales and its species, Methanobrevibacter 
gottschalkii clade, Methanobrevibacter boviskoreani clade, and Methanobrevibacter ruminantium clade, were most abundant archaeal taxa in the rumen of $\mathrm{Hu}$ sheep. Methanobrevibacter belonging to the family Methanobacteriaceae, mainly utilizes hydrogen and carbon dioxide to produce methane $[67,68]$. Methanotorris belonging to the family Methanocaldococcaceae is the methanogen that uses hydrogen, carbon dioxide, and formate as the substrates to produce methane [69]. These two archaeal taxa are recognized as the methanogens with high methane conversion capacity [70]. According to the LEfSe analysis of the loosely attached fraction, the bio-fermentation reduced the relative abundance of Methanosphaera belonging to the family Methanocaldococcaceae, which has the greater methane conversion capacity as mentioned above. In the tightly attached fraction, the genera group 4 and group 10, belonging to the family Methanomassiliicoccaceae, were higher for the RS and the BFRS, respectively. These archaeal taxa produce methane by the reduction of methanol or methylamines, which contributes to lower methane emissions [71,72]. Jin et al. [25] reported that Methanomassiliicoccales are probably less important contributors to the rumen methane emission of Chinese goats because of their low relative abundance among the archaeal community. For this reason, the bio-fermentation could have reduced the methane concentration in the total gas volume for the RS.

\section{Conclusions}

The bio-fermentation altered the tightly attached bacterial community, thereby improving gas production, fiber degradation, and fermentation products. Furthermore, the bio-fermentation reduced methane concentration in total gas volume without affecting the archaeal community. Our results confirmed that bio-fermentation improved rumen fermentation effectively, and deepened our understanding of the colonization pattern and compositional changes of the rumen microbiome. This suggests the need to conduct further research on the effect of the bio-fermentation on the physicochemical structure of rice straw, as well as hydrogen production and utilization by ruminal microorganisms, with a focus on methane conversion efficiency.

Supplementary Materials: The following supporting information can be downloaded at: https: / / www.mdpi.com/article/10.3390/fermentation8020072/s1, Table S1. Chemical compositions of substrates. Figure S1. LEfSe analysis of the loosely attached bacteria (A), and archaea (B), and tightly attached archaea (C). RS: rice straw, BFRS: bio-fermented rice straw.

Author Contributions: Methodology, Y.X. and M.A.; investigation, Y.X., M.A., L.H., Z.S. and V.P.; formal analysis, Y.X., M.A. and Y.Z.; data curation, Y.X., M.A. and Y.Z.; writing-original draft preparation, Y.X.; writing-review and editing, M.A., Z.S., L.H., Y.C., V.P. and W.Z.; supervision, Y.C.; project administration, Y.C. and V.P.; funding acquisition, Y.C., W.Z. and V.P. All authors have read and agreed to the published version of the manuscript.

Funding: This research was funded by the National Natural Science Foundation of China, grant number 32061143034.

Institutional Review Board Statement: Not applicable.

Informed Consent Statement: Not applicable.

Data Availability Statement: The data of the 16S rRNA gene sequences of gut microbiota presented in this study can be available from the NCBI database (https:/ / www.ncbi.nlm.nih.gov/genome/ (accessed on 10 January 2022)) under accession number PRJNA795694.

Acknowledgments: This research has been funded by the National Natural Science Foundation of China through project number 32061143034.

Conflicts of Interest: The authors declare no conflict of interest. 


\section{References}

1. Yu, Q.; Zhuang, X.S.; Wang, W.; Qi, W.; Wang, Q.; Tan, X.S.; Kong, X.Y.; Yuan, Z.H. Hemicellulose and lignin removal to improve the enzymatic digestibility and ethanol production. Biomass Bioenergy 2016, 94, 105-109. [CrossRef]

2. Wanapat, M.; Polyorach, S.; Boonnop, K.; Mapato, C.; Cherdthong, A. Effects of treating rice straw with urea or urea and calcium hydroxide upon intake, digestibility, rumen fermentation and milk yield of dairy cows. Livest. Sci. 2009, 125, 238-243. [CrossRef]

3. Bhutto, A.W.; Qureshi, K.; Harijan, K.; Abro, R.; Abbas, T.; Bazmi, A.A.; Karim, S.; Yu, G.R. Insight into progress in pre-treatment of lignocellulosic biomass. Energy 2017, 122, 724-745. [CrossRef]

4. Tuyen, V.D.; Cone, J.W.; Baars, J.J.P.; Sonnenberg, A.S.M.; Hendriks, W.H. Fungal strain and incubation period affect chemical composition and nutrient availability of wheat straw for rumen fermentation. Bioresource Technol. 2012, 111, 336-342. [CrossRef] [PubMed]

5. Xing, L. Study on the Effects of Lactobacillus and Cellulase Additives on the Quality of Different Silages. Master's Thesis, China Agricultural University, Beijing, China, 2004. (In Chinese).

6. Li, J.; Shen, Y.X.; Cai, Y.M. Improvement of Fermentation Quality of Rice Straw Silage by Application of a Bacterial Inoculant and Glucose. Asian Australas. J. Anim. 2010, 23, 901-906. [CrossRef]

7. Khota, W.; Pholsen, S.; Higgs, D.; Cai, Y.M. Fermentation quality and in vitro methane production of sorghum silage prepared with cellulase and lactic acid bacteria. Asian Australas. J. Anim. 2017, 30, 1568-1574. [CrossRef]

8. Zilber-Rosenberg, I.; Rosenberg, E. Role of microorganisms in the evolution of animals and plants: The hologenome theory of evolution. Fems Microbiol. Rev. 2008, 32, 723-735. [CrossRef]

9. Yanez-Ruiz, D.R.; Abecia, L.; Newbold, C.J. Manipulating rumen microbiome and fermentation through interventions during early life: A review. Front. Microbiol. 2015, 6, 1133. [CrossRef]

10. Wang, Y.; McAllister, T.A. Rumen microbes, enzymes and feed digestion - A review. Asian Australas. J. Anim. 2002, 15, 1659-1676. [CrossRef]

11. Mackie, R.I. Mutualistic fermentative digestion in the gastrointestinal tract: Diversity and evolution. Integr. Comp. Biol. 2002, 42, 319-326. [CrossRef]

12. Jami, E.; Mizrahi, I. Composition and Similarity of Bovine Rumen Microbiota across Individual Animals. PLoS ONE 2012, 7 , e33306. [CrossRef] [PubMed]

13. Liu, J.H.; Zhang, M.L.; Xue, C.X.; Zhu, W.Y.; Mao, S.Y. Characterization and comparison of the temporal dynamics of ruminal bacterial microbiota colonizing rice straw and alfalfa hay within ruminants. J. Dairy Sci. 2016, 99, 9668-9681. [CrossRef] [PubMed]

14. Cheng, Y.F.; Wang, Y.; Li, Y.F.; Zhang, Y.P.; Liu, T.Y.; Wang, Y.; Sharpton, T.J.; Zhu, W.Y. Progressive Colonization of Bacteria and Degradation of Rice Straw in the Rumen by Illumina Sequencing. Front. Microbiol. 2017, 8, 2165. [CrossRef] [PubMed]

15. Petri, R.M.; Forster, R.J.; Yang, W.; McKinnon, J.J.; McAllister, T.A. Characterization of rumen bacterial diversity and fermentation parameters in concentrate fed cattle with and without forage. J. Appl. Microbiol. 2012, 112, 1152-1162. [CrossRef]

16. Yang, C.T.; Si, B.W.; Diao, Q.Y.; Jin, H.; Zeng, S.Q.; Tu, Y. Rumen fermentation and bacterial communities in weaned Chahaer lambs on diets with different protein levels. J. Integr. Agric. 2016, 15, 1564-1574. [CrossRef]

17. Mould, F.L.; Kliem, K.E.; Morgan, R.; Mauricio, R.M. In vitro microbial inoculum: A review of its function and properties. Anim. Feed Sci. Technol. 2005, 123, 31-50. [CrossRef]

18. Zapletalova, M.; Kasparovska, J.; Krizova, L.; Kasparovsky, T.; Sery, O.; Lochman, J. Bacterial community dynamics in a rumen fluid bioreactor during in-vitro cultivation. J. Biotechnol. 2016, 234, 43-49. [CrossRef]

19. Menke, K.H.; Steingass, H. Estimation of the energetic feed value obtained from chemical analysis and in vitro gas production using rumen fluid. Anim. Res. Dev. 1988, 28, 7-55.

20. Theodorou, M.K.; Williams, B.A.; Dhanoa, M.S.; Mcallan, A.B.; France, J. A Simple Gas-Production Method Using a Pressure Transducer to Determine the Fermentation Kinetics of Ruminant Feeds. Anim. Feed Sci. Technol. 1994, 48, 185-197. [CrossRef]

21. Larue, R.; Yu, Z.T.; Parisi, V.A.; Egan, A.R.; Morrison, M. Novel microbial diversity adherent to plant biomass in the herbivore gastrointestinal tract, as revealed by ribosomal intergenic spacer analysis and rrs gene sequencing. Environ. Microbiol. 2005, 7 , 530-543. [CrossRef]

22. AOAC. Official Methods of Analysis of the Association of the Official Analysis Chemists, 15th ed.; AOAC International Publisher: Washington, DC, USA, 1990.

23. Van Soest, P.J.; Robertson, J.B.; Lewis, B.A. Methods for Dietary Fiber, Neutral Detergent Fiber, and Nonstarch Polysaccharides in Relation to Animal Nutrition. J. Dairy Sci. 1991, 74, 3583-3597. [CrossRef]

24. Weatherburn, M. Phenol-hypochlorite reaction for determination of ammonia. Anal. Chem. 1967, 39, 971-974. [CrossRef]

25. Jin, W.; Cheng, Y.F.; Zhu, W.Y. The community structure of Methanomassiliicoccales in the rumen of Chinese goats and its response to a high-grain diet. J. Anim. Sci. Biotechnol. 2017, 8, 47. [CrossRef]

26. Li, Y.F.; Jin, W.; Cheng, Y.F.; Zhu, W.Y. Effect of the Associated Methanogen Methanobrevibacter thaueri on the Dynamic Profile of End and Intermediate Metabolites of Anaerobic Fungus Piromyces sp F1. Curr. Microbiol. 2016, 73, 434-441. [CrossRef]

27. Zoetendal, E.G.; Akkermans, A.D.L.; De Vos, W.M. Temperature gradient gel electrophoresis analysis of 16S rRNA from human fecal samples reveals stable and host-specific communities of active bacteria. Appl. Environ. Microbiol. 1998, 64, 3854-3859. [CrossRef] [PubMed] 
28. Caporaso, J.G.; Lauber, C.L.; Walters, W.A.; Berg-Lyons, D.; Lozupone, C.A.; Turnbaugh, P.J.; Fierer, N.; Knight, R. Global patterns of 16S rRNA diversity at a depth of millions of sequences per sample. Proc. Natl. Acad. Sci. USA 2011, 108, 4516-4522. [CrossRef] [PubMed]

29. Kittelmann, S.; Seedorf, H.; Walters, W.A.; Clemente, J.C.; Knight, R.; Gordon, J.I.; Janssen, P.H. Simultaneous Amplicon Sequencing to Explore Co-Occurrence Patterns of Bacterial, Archaeal and Eukaryotic Microorganisms in Rumen Microbial Communities. PLoS ONE 2013, 8, e47879. [CrossRef]

30. Bolger, A.M.; Lohse, M.; Usadel, B. Trimmomatic: A flexible trimmer for Illumina sequence data. Bioinformatics 2014, 30, 2114-2120 [CrossRef]

31. Caporaso, J.G.; Kuczynski, J.; Stombaugh, J.; Bittinger, K.; Bushman, F.D.; Costello, E.K.; Fierer, N.; Pena, A.G.; Goodrich, J.K.; Gordon, J.I.; et al. QIIME allows analysis of high-throughput community sequencing data. Nat. Methods 2010, 7, 335-336. [CrossRef]

32. Shoskes, D.; Altemus, J.; Polackwich, A.; Tucky, B.; Wang, H.; Eng, C. Analysis of Gut Microbiome Reveals Significant Differences between Men with Chronic Prostatitis/Chronic Pelvic Pain Syndrome and Controls. J. Urol. 2016, 195, E451-E452. [CrossRef]

33. De Boever, J.L.; Aerts, J.M.; Vanacker, J.M.; De Brabander, D.L. Evaluation of the nutritive value of maize silages using a gas production technique. Anim. Feed Sci. Technol. 2005, 123, 255-265. [CrossRef]

34. Oladosu, Y.; Rafii, M.Y.; Abdullah, N.; Magaji, U.; Hussin, G.; Ramli, A.; Miah, G. Fermentation Quality and Additives: A Case of Rice Straw Silage. Biomed. Res. Int. 2016, 2016, 7985167. [CrossRef] [PubMed]

35. Van Soest, P.J. Fibre and physicochemical properties of feeds. In Nutritional Ecology of the Ruminant, 2nd ed.; Thomas, L.P., Ed.; Cornell University Press: Ithaca, NY, USA, 1994.

36. Blümmel, M.; Becker, K. The degradability characteristics of fifty-four roughages and roughage neutral-detergent fibres as described by in vitro gas production and their relationship to voluntary feed intake. Br. J. Nutr. 1997, 77, 757-768. [CrossRef] [PubMed]

37. Sallam, S.; Abdalla, A.L.; Nozella, E.F.; Bueno, I.; Vitti, D.; Godoy, P.B. Nutritive value assessment of the artichoke (Cynara scolymus) by-product as an alternative feed resource for ruminants. Trop. Subtrop. Agroecosyst. 2008, 8, 181-189.

38. Zhang, X.M.; Wang, M.; Wang, R.; Ma, Z.Y.; Long, D.L.; Mao, H.X.; Wen, J.N.; Bernard, L.A.; Beauchemin, K.A.; Tan, Z.L. Urea plus nitrate pretreatment of rice and wheat straws enhances degradation and reduces methane production in in vitro ruminal culture. J. Sci. Food Agric. 2018, 98, 5205-5211. [CrossRef]

39. Gharechahi, J.; Vahidi, M.F.; Ding, X.Z.; Han, J.L.; Salekdeh, G.H. Temporal changes in microbial communities attached to forages with different lignocellulosic compositions in cattle rumen. Fems Microbiol. Ecol. 2020, 96, fiaa069. [CrossRef]

40. Kafilzadeh, F.; Heidary, N. Chemical composition, in vitrodigestibility and kinetics of fermentation of whole-crop forage from 18 different varieties of oat (Avena sativa L.). J. Appl. Anim. Res. 2013, 41, 61-68. [CrossRef]

41. Getachew, G.; Robinson, P.H.; DePeters, E.J.; Taylor, S.J. Relationships between chemical composition, dry matter degradation and in vitro gas production of several ruminant feeds. Anim. Feed Sci. Technol. 2004, 111, 57-71. [CrossRef]

42. Patra, A.K.; Aschenbach, J.R. Ureases in the gastrointestinal tracts of ruminant and monogastric animals and their implication in urea-N/ammonia metabolism: A review. J. Adv. Res. 2018, 13, 39-50. [CrossRef]

43. Jin, D.; Zhao, S.G.; Zheng, N.; Beckers, Y.; Wang, J.Q. Urea Metabolism and Regulation by Rumen Bacterial Urease in Ruminants a Review. Ann. Anim. Sci. 2018, 18, 303-318. [CrossRef]

44. Zened, A.; Combes, S.; Cauquil, L.; Mariette, J.; Klopp, C.; Bouchez, O.; Troegeler-Meynadier, A.; Enjalbert, F. Microbial ecology of the rumen evaluated by 454 GS FLX pyrosequencing is affected by starch and oil supplementation of diets. Fems Microbiol. Ecol. 2013, 83, 504-514. [CrossRef] [PubMed]

45. Metzler-Zebeli, B.U.; Schmitz-Esser, S.; Klevenhusen, F.; Podstatzky-Lichtenstein, L.; Wagner, M.; Zebeli, Q. Grain-rich diets differently alter ruminal and colonic abundance of microbial populations and lipopolysaccharide in goats. Anaerobe 2013, 20, 65-73. [CrossRef]

46. El Kaoutari, A.; Armougom, F.; Gordon, J.I.; Raoult, D.; Henrissat, B. The abundance and variety of carbohydrate-active enzymes in the human gut microbiota. Nat. Rev. Microbiol. 2013, 11, 497-504. [CrossRef] [PubMed]

47. Naas, A.E.; Mackenzie, A.K.; Mravec, J.; Schuckel, J.; Willats, W.G.T.; Eijsink, V.G.H.; Pope, P.B. Do Rumen Bacteroidetes Utilize an Alternative Mechanism for Cellulose Degradation? mBio 2014, 5, e01401-14. [CrossRef] [PubMed]

48. Xie, F.; Zhang, L.L.; Jin, W.; Meng, Z.X.; Cheng, Y.F.; Wang, J.; Zhu, W.Y. Methane Emission, Rumen Fermentation, and Microbial Community Response to a Nitrooxy Compound in Low-Quality Forage Fed Hu Sheep. Curr. Microbiol. 2019, 76, $435-441$. [CrossRef]

49. Purushe, J.; Fouts, D.E.; Morrison, M.; White, B.A.; Mackie, R.I.; Coutinho, P.M.; Henrissat, B.; Nelson, K.E.; Bacteria, N.A.C.R. Comparative Genome Analysis of Prevotella ruminicola and Prevotella bryantii: Insights into Their Environmental Niche. Microbiol. Ecol. 2010, 60, 721-729. [CrossRef]

50. Dai, X.; Tian, Y.; Li, J.T.; Su, X.Y.; Wang, X.W.; Zhao, S.G.; Liu, L.; Luo, Y.F.; Liu, D.; Zheng, H.J.; et al. Metatranscriptomic Analyses of Plant Cell Wall Polysaccharide Degradation by Microorganisms in the Cow Rumen. Appl. Environ. Microbiol. 2015, 81, 1375-1386. [CrossRef]

51. Pitta, D.W.; Pinchak, W.E.; Dowd, S.E.; Osterstock, J.; Gontcharova, V.; Youn, E.; Dorton, K.; Yoon, I.; Min, B.R.; Fulford, J.D.; et al. Rumen Bacterial Diversity Dynamics Associated with Changing from Bermudagrass Hay to Grazed Winter Wheat Diets. Microbiol. Ecol. 2010, 59, 511-522. [CrossRef] 
52. Su, X.L.; Tian, Q.; Zhang, J.; Yuan, X.Z.; Shi, X.S.; Guo, R.B.; Qiu, Y.L. Acetobacteroides hydrogenigenes gen. nov., sp nov., an anaerobic hydrogen-producing bacterium in the family Rikenellaceae isolated from a reed swamp. Int. J. Syst. Evol. Microbiol. 2014, 64, 2986-2991. [CrossRef]

53. Agarussi, M.C.N.; Pereira, O.G.; de Paula, R.A.; da Silva, V.P.; Roseira, J.P.S.; Silva, F.F.E. Novel lactic acid bacteria strains as inoculants on alfalfa silage fermentation. Sci. Rep.-UK 2019, 9, 8007. [CrossRef]

54. Gharechahi, J.; Salekdeh, G.H. A metagenomic analysis of the camel rumen's microbiome identifies the major microbes responsible for lignocellulose degradation and fermentation. Biotechnol. Biofuels 2018, 11, 216. [CrossRef] [PubMed]

55. Lapebie, P.; Lombard, V.; Drula, E.; Terrapon, N.; Henrissat, B. Bacteroidetes use thousands of enzyme combinations to break down glycans. Nat. Commun. 2019, 10, 2043. [CrossRef] [PubMed]

56. Ren, H.; Huang, B.L.; Fernandez-Garcia, V.; Miesel, J.; Yan, L.; Lv, C.Q. Biochar and Rhizobacteria Amendments Improve Several Soil Properties and Bacterial Diversity. Microorganisms 2020, 8, 502. [CrossRef] [PubMed]

57. Suen, G.; Weimer, P.J.; Stevenson, D.M.; Aylward, F.O.; Boyum, J.; Deneke, J.; Drinkwater, C.; Ivanova, N.N.; Mikhailova, N.; Chertkov, O.; et al. The Complete Genome Sequence of Fibrobacter succinogenes S85 Reveals a Cellulolytic and Metabolic Specialist. PLoS ONE 2011, 6, e18814. [CrossRef]

58. Fukuma, N.M.; Koike, S.; Kobayashi, Y. Monitoring of gene expression in Fibrobacter succinogenes S85 under the co-culture with non-fibrolytic ruminal bacteria. Arch. Microbiol. 2015, 197, 269-276. [CrossRef]

59. Huws, S.A.; Edwards, J.E.; Creevey, C.J.; Stevens, P.R.; Lin, W.C.; Girdwood, S.E.; Pachebat, J.A.; Kingston-Smith, A.H. Temporal dynamics of the metabolically active rumen bacteria colonizing fresh perennial ryegrass. Fems Microbiol. Ecol. 2016, 92 , fiv137. [CrossRef]

60. Chen, S.Y.; Niu, L.L.; Zhang, Y.X. Saccharofermentans acetigenes gen. nov., sp nov., an anaerobic bacterium isolated from sludge treating brewery wastewater. Int. J. Syst. Evol. Microbiol. 2010, 60, 2735-2738. [CrossRef]

61. Li, Y.Q.; Hou, Z.S.; Shi, Q.C.; Cheng, Y.F.; Zhu, W.Y. Methane Production From Different Parts of Corn Stover via a Simple Co-culture of an Anaerobic Fungus and Methanogen. Front. Bioeng. Biotechnol. 2020, 8, 314. [CrossRef]

62. Koike, S.; Kobayashi, Y. Fibrolytic Rumen Bacteria: Their Ecology and Functions. Asian Australas. J. Anim. 2009, 22, 131-138. [CrossRef]

63. Fernando, S.C.; Purvis, H.T.; Najar, F.Z.; Sukharnikov, L.O.; Krehbiel, C.R.; Nagaraja, T.G.; Roe, B.A.; DeSilva, U. Rumen Microbial Population Dynamics during Adaptation to a High-Grain Diet. Appl. Environ. Microbiol. 2010, 76, 7482-7490. [CrossRef]

64. Johnson, K.A.; Johnson, D.E. Methane Emissions from Cattle. J. Anim. Sci. 1995, 73, 2483-2492. [CrossRef] [PubMed]

65. Kim, I.S.; Hwang, M.H.; Jang, N.J.; Hyun, S.H.; Lee, S.T. Effect of low pH on the activity of hydrogen utilizing methanogen in bio-hydrogen process. Int. J. Hydrog. Energ 2004, 29, 1133-1140. [CrossRef]

66. Huang, J.Q.; Li, Y.J. Rumen methanogen and protozoal communities of Tibetan sheep and Gansu Alpine Finewool sheep grazing on the Qinghai-Tibetan Plateau, China. BMC Microbiol. 2018, 18, 212. [CrossRef]

67. Janssen, P.H.; Kirs, M. Structure of the archaeal community of the rumen. Appl. Environ. Microbiol. 2008, 74, 3619-3625. [CrossRef]

68. Singh, A.L.; Singh, P.K.; Singh, M.P. Biomethanization of coal to obtain clean coal energy: A review. Energy Explor. Exploit. 2012, 30, 837-852. [CrossRef]

69. Maspolim, Y.; Zhou, Y.; Guo, C.H.; Xiao, K.K.; Ng, W.J. Comparison of single-stage and two-phase anaerobic sludge digestion systems - Performance and microbial community dynamics. Chemosphere 2015, 140, 54-62. [CrossRef]

70. Mauerhofer, L.M.; Zwirtmayr, S.; Pappenreiter, P.; Bernacchi, S.; Seifert, A.H.; Reischl, B.; Schmider, T.; Taubner, R.S.; Paulik, C.; Rittmann, S.K.M.R. Hyperthermophilic methanogenic archaea act as high-pressure CH4 cell factories. Commun. Biol. 2021, 4, 289. [CrossRef]

71. Lang, K.; Schuldes, J.; Klingl, A.; Poehlein, A.; Daniel, R.; Brune, A. New Mode of Energy Metabolism in the Seventh Order of Methanogens as Revealed by Comparative Genome Analysis of “Candidatus Methanoplasma termitum". Appl. Environ. Microbiol. 2015, 81, 1338-1352. [CrossRef]

72. Huang, X.D.; Tan, H.Y.; Long, R.J.; Liang, J.B.; Wright, A.D.G. Comparison of methanogen diversity of yak (Bos grunniens) and cattle (Bos taurus) from the Qinghai-Tibetan plateau, China. BMC Microbiol. 2012, 12, 237. [CrossRef] 